\title{
Coordinated Voltage and Reactive Power Control Scheme of HVAC Meshed Offshore Grid of Offshore Wind Power Plant at Kriegers Flak
}

\author{
Wu, Qiuwei; Takarics, Tibor; Akhmatov, Vladislav
}

Published in:

Proceedings of IET RPG 2019

Link to article, DOI:

$10.1049 / \mathrm{cp} .2019 .0258$

Publication date:

2020

Document Version

Peer reviewed version

Link back to DTU Orbit

Citation (APA):

Wu, Q., Takarics, T., \& Akhmatov, V. (2020). Coordinated Voltage and Reactive Power Control Scheme of HVAC Meshed Offshore Grid of Offshore Wind Power Plant at Kriegers Flak. In Proceedings of IET RPG 2019 Institution of Engineering and Technology. https://doi.org/10.1049/cp.2019.0258

\section{General rights}

Copyright and moral rights for the publications made accessible in the public portal are retained by the authors and/or other copyright owners and it is a condition of accessing publications that users recognise and abide by the legal requirements associated with these rights.

- Users may download and print one copy of any publication from the public portal for the purpose of private study or research.

- You may not further distribute the material or use it for any profit-making activity or commercial gain

- You may freely distribute the URL identifying the publication in the public portal 


\section{Coordinated Voltage and Reactive Power Control Scheme of HVAC Meshed Offshore Grid of Offshore Wind Power Plant at Kriegers Flak Qiuwei Wu $^{1 *}$, Tibor Takarics ${ }^{1}$, Vladislav Akhmatov ${ }^{2}$ \\ ${ }^{1}$ Technical University of Denmark, Kgs. Lyngby, Denmark \\ ${ }^{2}$ Energinet, Transmission System Operator of Denmark, Fredericia, Denmark \\ *qw@elektro.dtu.dk}

Keywords: Voltage and Reactive Power Control, Offshore Wind Power, Meshed Offshore Grid, Hybrid-Asset.

\begin{abstract}
The Kriegers Flak Combined Grid Solution (KF CGS) is the first hybrid-asset project utilizing an offshore HVAC/HVDC interconnector through already established and undercommissioning large offshore wind power plants between East Denmark and Germany in the Baltic Sea. In total, the KF CGS utilizes above $520 \mathrm{~km}$ HVAC cables, and, in the Danish side, above $200 \mathrm{~km} 220 \mathrm{kV}$ cables arranged into a meshed offshore transmission grid. As the cables approach critical lengths, the reactive power generation is dependant on the active power transfer. In the Danish side, the control is realized by an automatic voltage and reactive power control (AVR/RPC) of several switchable and variable reactors and transformers with tap-position controllers, and the Wind Power Plant Controllers (WPPC). In the German side, the voltage control is achieved by the HVDC Back-to-Back and WPPC and part of the Optimal Power Flow (OPF) by the Master Controller for Interconnector Operation (MIO). This paper introduces the overall control of the KF CGS and presents the proposed coordinated voltage and reactive power control and assets on the Danish side of the KF CGS interconnector.
\end{abstract}

\section{Introduction}

The Kriegers Flak Combined Grid Solution (KF CGS) is a hybrid-asset project of Energinet, the Transmission System Operator (TSO) of Denmark, and 50Hertz Transmission, the German TSO in the Baltic Sea [1]. The term hybrid-asset means that the KF CGS is an offshore interconnector between the two transmission systems, i.e., East Denmark and Germany, which utilizes the grid-connections of the large offshore wind power plants (OWPP) [2]. Fig. 1 gives an overview of the KF CGS including the wind power plants, offshore platforms, substations and cables. The KF CGS connects the wind power infeed and permits the remaining capacity to be utilized by the market.

The already existing $135 \mathrm{~km}$ long $150 \mathrm{kV}$ AC submarine and underground cable connections of the Baltic 1 (48.3 MW) and Baltic 2 (288 MW) wind power plants are extended by the two $24 \mathrm{~km}$ long $150 \mathrm{kV}$ AC cables from the reconfigured Baltic 2 platform to the new Kriegers Flak B extension platform (KFE). At the Danish side, the two platforms Kriegers Flak A (KFA) and Kriegers Flak B (KFB) are established to collect $200 \mathrm{MW}$ and $400 \mathrm{MW}$ offshore wind power, respectively. The KFA and KFB platforms are linked through an approx. $9 \mathrm{~km}$ long $220 \mathrm{kV}$ AC cable and connected to the onshore compensation substation Bjæverskov via two approx. $80 \mathrm{~km}$ long $220 \mathrm{kV}$ submarine and underground cables. In Bjæverskov, there is a 400/220 $\mathrm{kV}$ step-up transformation with connection to the East Danish $400 \mathrm{kV}$ transmission grid. From Bjæverskov to Ishøj, there is another $35 \mathrm{~km}$ long $220 \mathrm{kV}$ underground cable with another $400 / 220 \mathrm{kV}$ step-up transformation to the $400 \mathrm{kV}$ grid.

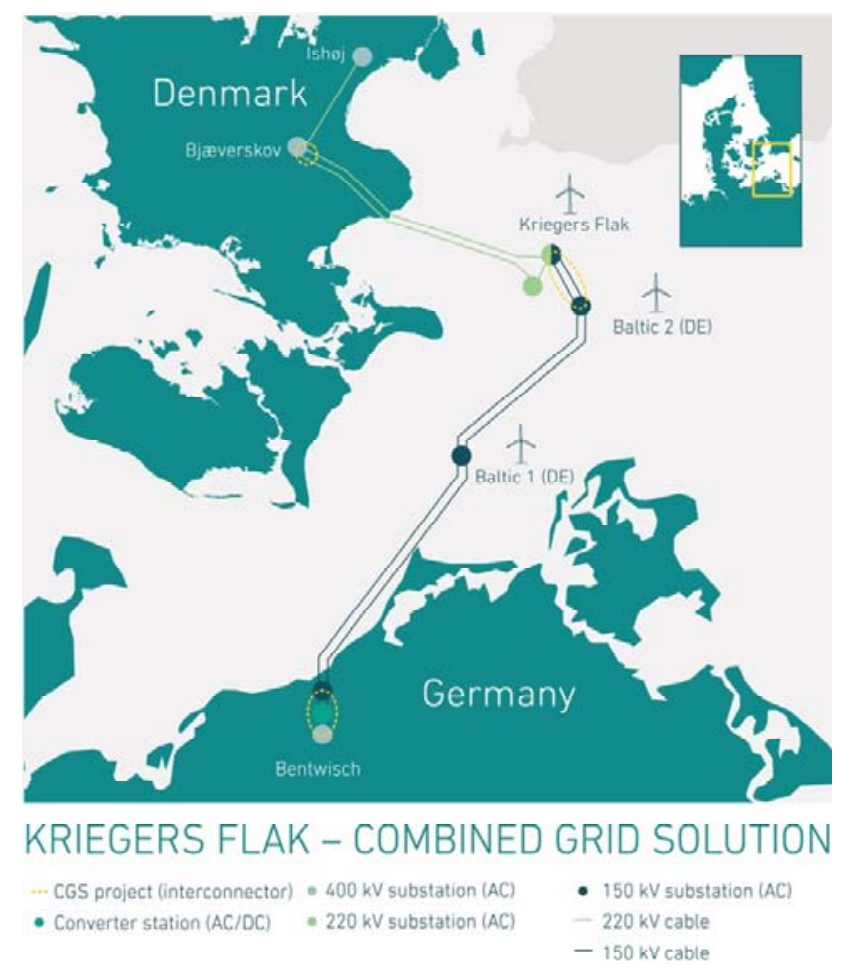

Fig. 1 Overview of Kriegers Flak Combined Grid Solution as a hybrid-asset interconnector in the Baltic Sea between East Denmark and Germany via the Baltic 1, Baltic 2, Kriegers Flak A and Kriegers Flak B offshore wind power plants.

On the KFE platform, the $220 / 150 \mathrm{kV}$ transformation is established which connects the $220 \mathrm{kV}$ meshed offshore grid with the $150 \mathrm{kV}$ radial grid (parallel cables). At present, the $150 \mathrm{kV}$ terminal of the KFE platform serves as the point-of- 
settlement between Denmark and Germany with the nominal active power transfer capacity of $+/-400 \mathrm{MW}$ and the allowed reactive power exchange of $+/-40$ MVAR.

Since East Denmark (Nordic synchronous area) and Germany (Continental European synchronous area) are not synchronised, there is an HVDC Back-to-Back converter (BtB) in the German substation Bentwisch. The active and reactive ratings of the $\mathrm{BtB}$ are $400 \mathrm{MW}$ and $100 \mathrm{MVAR}$.

\section{Control Principles}

The control is established for keeping the voltages and reactive power transfer via the KFE platform and with the Danish $400 \mathrm{kV}$ transmission grid within specified operation ranges [3]. Minimizing the reactive power transfer is for reducing the transmission losses.

The WWPC and BtB delivers continuous voltage control and the tap-position controllers of the transformers and reactors provide discrete stepwise voltage and reactive power control. Since the assets and control systems are distributed through the entire length of the KF CGS, i.e., about $250 \mathrm{~km}$, the control is divided in the middle of the interconnector, i.e., between the $220 \mathrm{kV}$ and $150 \mathrm{kV}$ networks, as shown in Fig. 2 .

The $220 \mathrm{kV}$ and $150 \mathrm{kV}$ networks are treated as two separate areas regarding voltage and reactive power control with less possible interaction. This is enforced by permitting only a minor reactive power exchange via the $220 / 150 \mathrm{kV}$ transformer at the KFE platform and letting the KFE transformer control the $150 \mathrm{kV}$ terminal voltage (for interconnected operation regimes).

In the $150 \mathrm{kV}$ area, the Master Controller for Interconnector Operation (MIO) conducts the Optimal Power Flow (OPF) by optimizing the voltages of the Baltic 1 and Baltic 2 WPPC and $\mathrm{BtB}$. In the $220 \mathrm{kV}$ area, the AVR/RPC controls the tapposition controllers of the transformers and reactors.
The initial studies have shown a strong viability of dynamic reactive power transfer through the KFE platform under varying operation conditions of the offshore wind power plants in the $150 \mathrm{kV}$ network, which can trigger excessive utilization of the tap-positions controlled by the AVR/RPC in the $220 \mathrm{kV}$ network. Further, inherent dynamic variations of the Danish transmission grid voltage can also contribute to utilization of the tap-positions by the AVR/RPC. Therefore, the KFA and KFB WPPC shall together with the AVR/RPC establish a coordinated control mitigating such unwished effects and reduce stepping of the discrete components.

\section{AVR/RPC Scheme}

The $220 \mathrm{kV}$ area includes the meshed $220 \mathrm{kV}$ cable system collecting the KFA and KFB platforms with the compensation substation BJS 220 and, further, with the Danish $400 \mathrm{kV}$ transmission grid. The nominal power transfer capacity of the submarine cables is $300 \mathrm{MW}$ and that of the underground cables is $500 \mathrm{MW}$ plus their reactive power generation. The provided capacities do not account for the dynamic line rating (DLR) of the $220 \mathrm{kV}$ cables [4].

The relevant assets are shown in Fig. 3 and include the tapchangers of the 500 MVA $400 / 220 / 10 \mathrm{kV}$ TA1 and TA2 transformers in Bjæverskov and Ishøj, the tap-changer of the 450 MVA $220 / 150 \mathrm{kV}$ TA3 offshore transformer on the KFE platform, and the 120 MVAR switchable and 60-120 MVAR variable reactors in BJS 220 and on the KFA platform. These components are controlled by the Danish AVR/RPC.

The TA1 and TA2 tap-changers are set to maintain the $220 \mathrm{kV}$ platform voltage within a given voltage band, i.e., the AVR. The default voltage band is $235-239 \mathrm{kV}$ on the platforms, but adaptable from the National Control Centre (NCC) in Denmark. During normal n-0 conditions, these transformers are in a master-follower regime. If the busbar voltage anywhere in the $220 \mathrm{kV}$ system gets over the highest permitted voltage, the TA1 and TA2 transformers immediately interfere and step the voltage down.

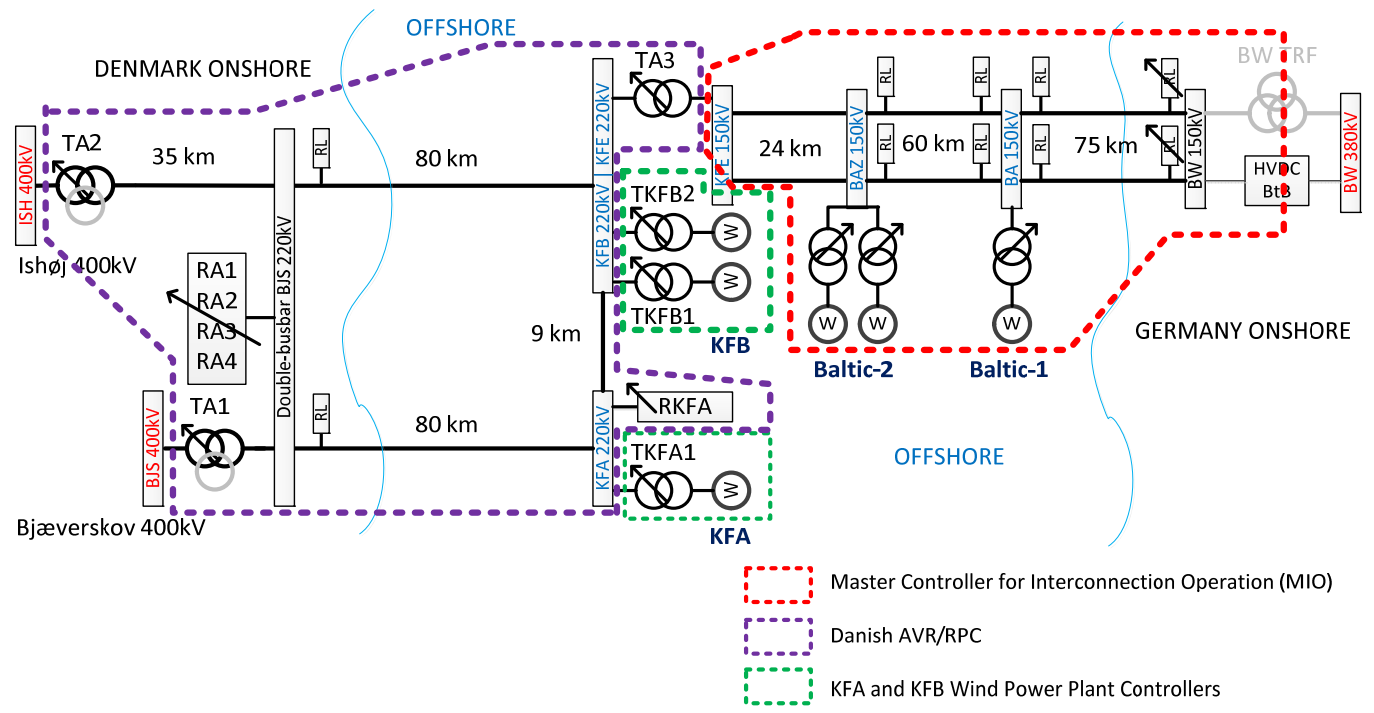

Fig. 2 Voltage and reactive power control principles of Kriegers Flak Combined Grid Solution. 


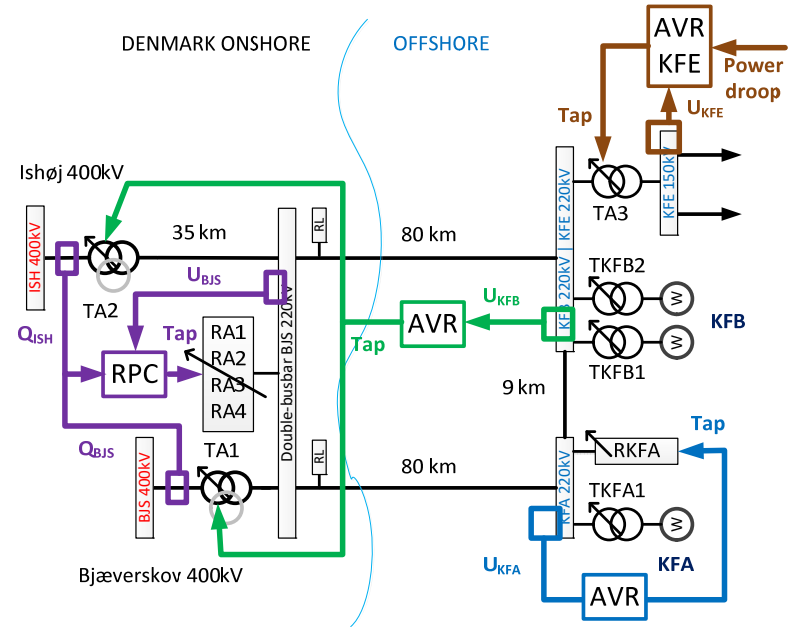

Fig. 3 Schematic representation of the AVR/RPC in the 220 $\mathrm{kV}$ area of Kriegers Flak Combined Grid Solution.

These transformers remain in the master-follower regime in all interconnected operation scenarios except the fully separated regime, i.e., both the busbars of the Bjæverskov substation and the KFA and KFB platforms are separated. The AVR takes into account the cross-coupling variants between the transformers and platforms when the Bjæverskov substation is in separated operation. When one transformer is out of operation, the remaining transformer is a single master.

The control of the reactors in the compensation substation in Bjæverskov shall keep the reactive-power exchange between the KF CGS and the Danish $400 \mathrm{kV}$ grid within a given band. The default value of the band is \pm 20 MVAR with the reference of $0 \mathrm{MVAR}$ in each $400 \mathrm{kV}$ connection point, but adaptable from the NCC. The reactors can be connected to either one of the busbars of the substation. In coupled operation of the substation, which is shown in Fig. 3, the reactive power control works as a single RPC system for all the reactors and secures that the absolute maximum reactive power exchange in either Bjæverskov or Ishøj stays within the band, e.g., \pm 20 MVAR. In separated operation of the substation, the reactive power control splits into two RPC systems. Each RPC is keeping the reactive power exchange with its connected $400 \mathrm{kV}$ terminal. When the connection to one of the $400 \mathrm{kV}$ terminals is removed, the RPC works with the $400 \mathrm{kV}$ terminal which remains connected to the compensation substation.

Since the first steps of the reactors, e.g., $60 \mathrm{MVAR}$, are larger than the +/-20 MVAR reactive power band, the RPC precalculates the reactive power after switching the reactor. Only if the switching gives a more favourable reactive power position, the RPC conducts the switching. If not, the switching is not conducted and the reactive power exchange can have a small offset from the reactive power band.

Besides, the RPC monitors the voltage in the Bjæverskov substation. If the voltage gets off range, the control regime shifts from the reactive power control to the voltage control. In the voltage control regime, fast switching of the reactors may apply. However, excessive switching off is prevented for avoiding unexpected overvoltage situations.

The switchable reactor on the KFA platform does not participate in the reactive power control. This reactor is normally in-service, which is disconnected by undervoltage and re-connected by overvoltage on the KFA platform. This AVR control is illustrated in Fig. 3.

\section{Test and Model Validation}

On May $2^{\text {nd }} 2019$, the AVR/RPC was tested for the first time and under supervision of the NCC. The test operation has provided the real-life data which are applied for the AVR/RPC simulation model validation. Prior to the test, the AVR/RPC has been inactive with locked tap-positions of the transformers and variable reactors. The test begins from the transformer tap-position at 9 giving $230 \mathrm{kV}$ in the offshore platforms, and all reactors are connected causing about 200 MVAR absorption from the $400 \mathrm{kV}$ transmission grid. The test duration was over 3 hours with the following events

1 Automatic voltage control (AVR) of the transformer is released. The tap-position steps up to follow the given voltage reference $233 \mathrm{kV}$.

2 The voltage reference is $235 \mathrm{kV}$. The tap-position steps up to follow the reference.

3 The voltage reference is $237 \mathrm{kV}$. The tap-position steps up to follow the reference.

4 The voltage reference is $230 \mathrm{kV}$. The tap-position steps down to follow the reference.

5 The voltage reference is $237 \mathrm{kV}$. The tap-position steps up to follow the reference.

6 The grid voltage sags causing a single toggle of the tap-position. Not included in the calculations.

7 Reactive power control (RPC) of the reactors is released. The reference is set to $0 \mathrm{MVAR}$ and the band to $+/-100$ MVAR. The reactors step down in specified priority to complete the operation band.

8 The band is reduced to +/-70 MVAR. The reactors step down in specified priority to complete the operation band.

9 The band is reduced to +/-50 MVAR. The reactors step down in specified priority to complete the operation band.

10 The band is reduced to +/-20 MVAR. The reactors step down in specified priority. The operation is few MVAR off the band. All reactors are in the first steps and further stepping-down may cause unfavourable conditions.

11 The reference is set to 10 MVAR (capacitive) to provoke the first reactor to switch off. A single reactor switches off as expected.

12 The reference is set to 0 MVAR. The connected reactors step up in specified priority to complete the operation band.

13 The reactor with the first priority RA1 is locked. The reference is $10 \mathrm{MVAR}$ inductive. The reactor with the second priority steps up to complete the operation band. 
14 The reference is $20 \mathrm{MVAR}$ inductive. The reactor with the second priority steps up to complete the operation band, as the first reactor is still locked.

15 The first reactor is unlocked.

16 The first reactor steps up due to varying conditions in the Danish transmission grid and manual actions of the NCC. Not included in the calculations.

17 The NCC disconnects the $220 \mathrm{kV}$ cable between the KFA and KFB platforms.

18 The NCC reconnects the $220 \mathrm{kV}$ cable between the KFA and KFB platforms. The cable discharging time before reconnection is not included in calculations.

19 The NCC manually steps all reactors in their first tap- positions and manually steps the transformer. Omitted in the calculations.

Fig. 4 shows the measured sequence from the AVR/RPC test operation. The measured data resolution is $1 \mathrm{~min}$. Attention is paid to that the $400 \mathrm{kV}$ voltage measurement in Bjæverskov is within a band of $1.5 \mathrm{kV}$, which is below $0.5 \%$ and accurate for operation.

Fig. 5 shows the calculated behaviour of the AVR/RPC model of Energinet implemented in the simulation program DigSilent ${ }^{\circledR}$ PowerFactory and applied in the presented work.

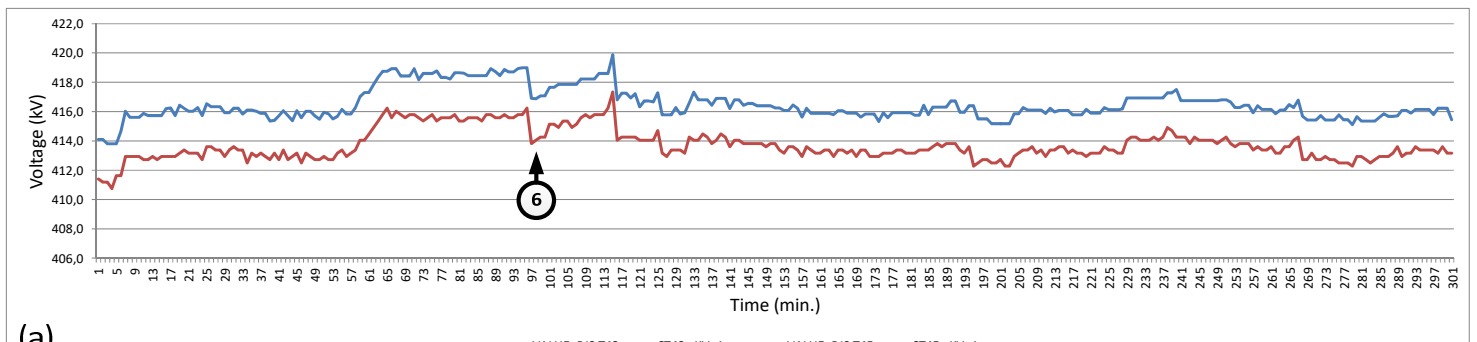

(a) —Value: BJS T43 CT43 KV_1 -Value: BJS T45 CT45 KV_1
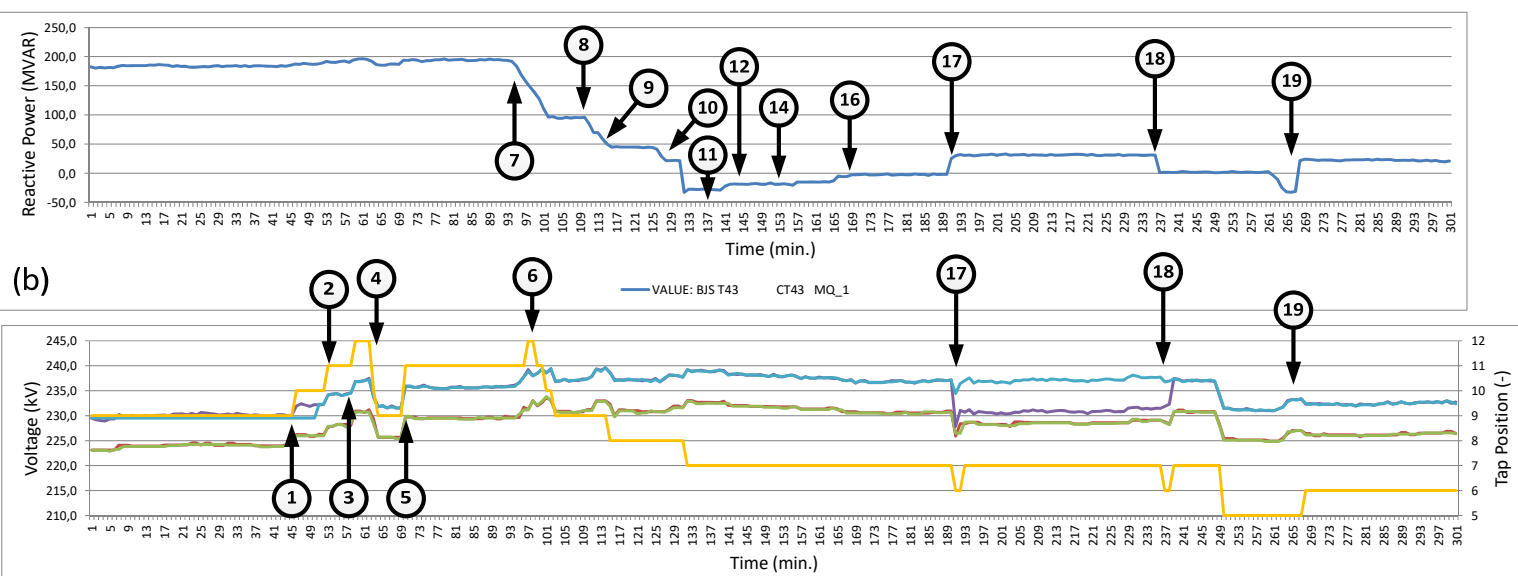

(c)

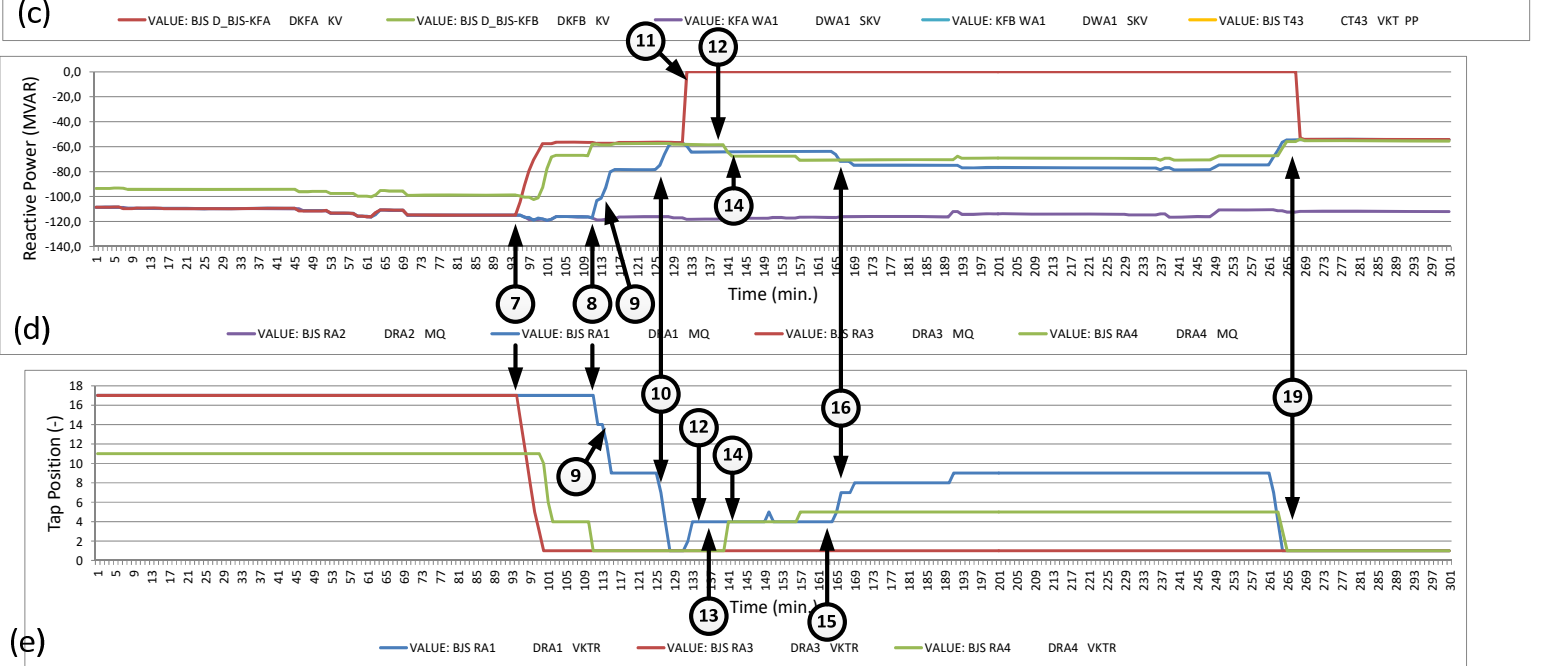

Fig. 4 Test operation of AVR/RPC (a) $400 \mathrm{kV}$ transmission grid voltage, (b) reactive power exchange with the transmission grid, positive is from the $400 \mathrm{kV}$ grid to the KF CGS, (c) $220 \mathrm{kV}$ voltage and 400/220/10 kV transformer tap-position, (d) reactors reactive power, (e) reactors tap-positions. 


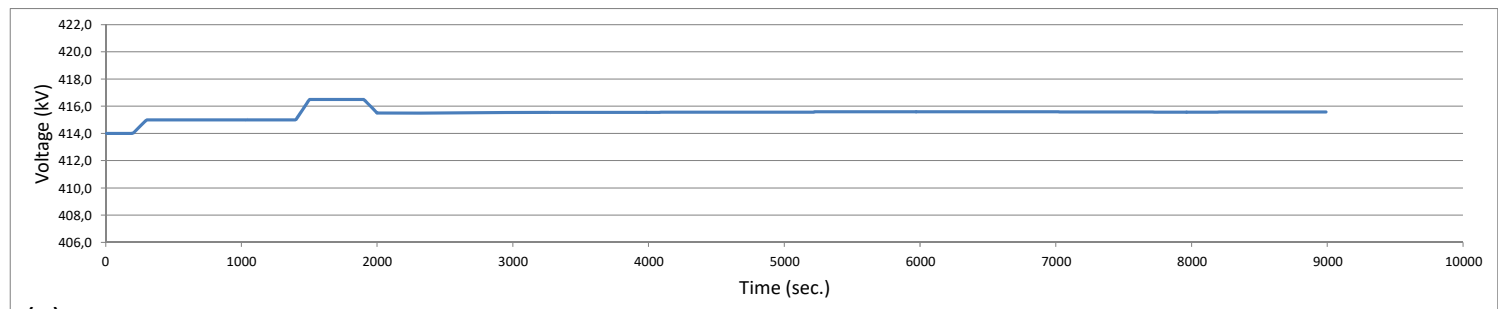

(a)

—BJS400 UI, Magnitude in kV
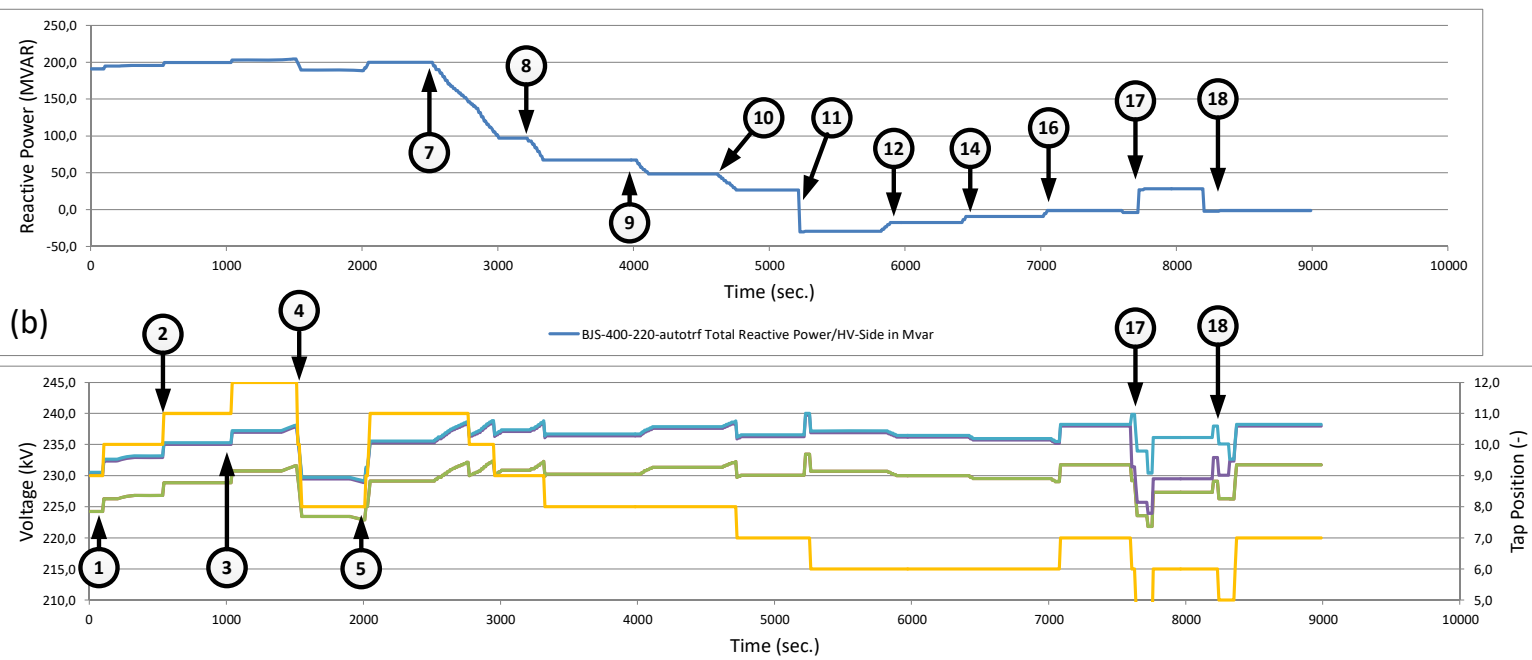

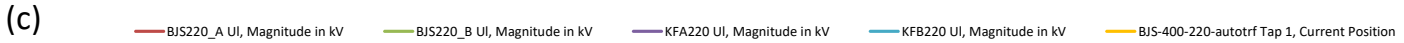

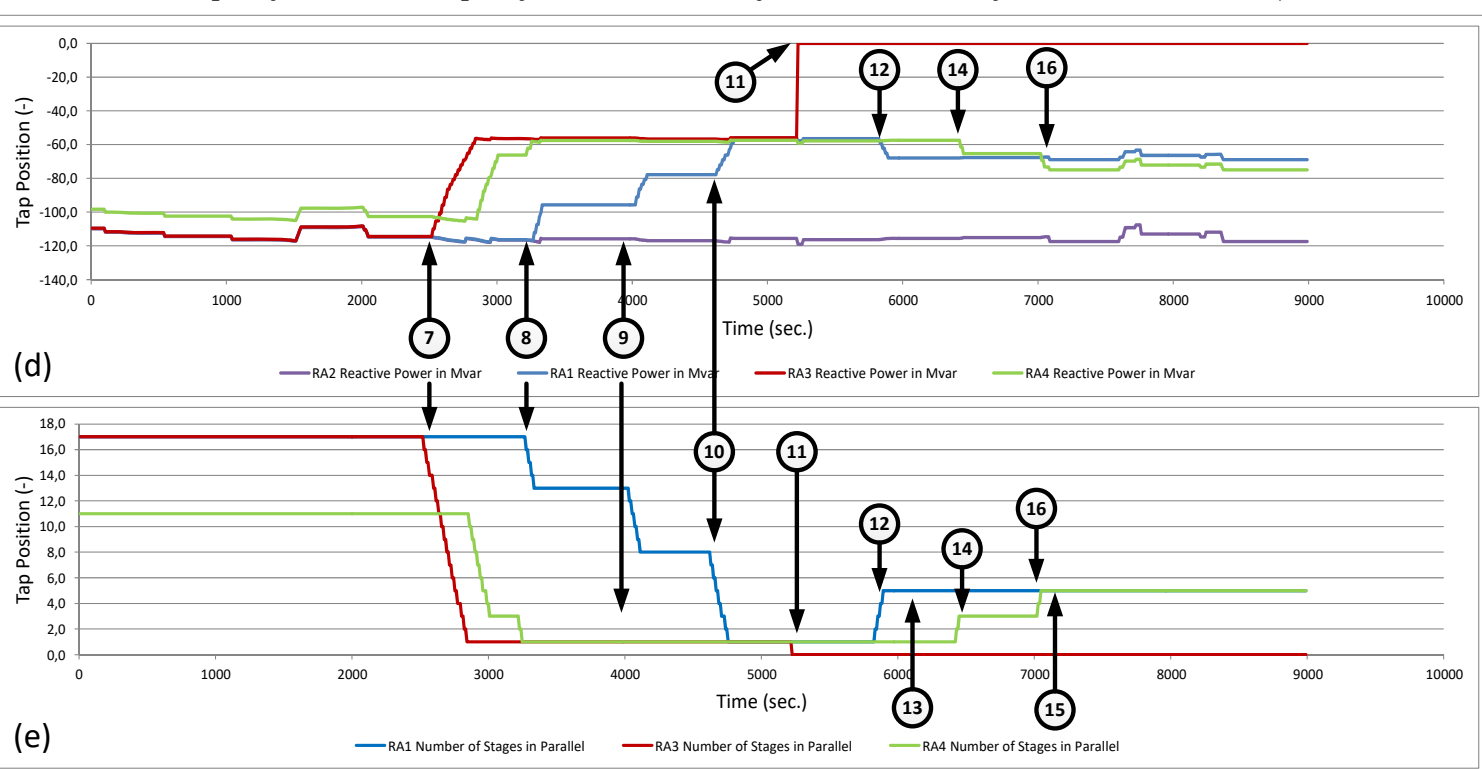

Fig. 5 Calculation of AVR/RPC using the simulation model of Energinet (a) $400 \mathrm{kV}$ transmission grid voltage, (b) reactive power exchange with the transmission grid, positive is from the $400 \mathrm{kV}$ grid to the $\mathrm{KF}$ CGS, (c) $220 \mathrm{kV}$ voltage and 400/220/10 kV transformer tap-position, (d) reactors reactive power, (e) reactors tap-positions.

The test operation sequences were manually conducted by the NCC judging the voltage and reactive power reaching a new steady-state. The exact time of the NCC actions and orders to the AVR/RPC was not recorded. Therefore, the calculations are conducted by giving orders in $500 \ldots 600$ seconds, i.e., not time-synchronised with the test. Further, a break by $15 \ldots 20$ min., when the KFA-KFB cable was switched-off, is shortened to $500 \mathrm{sec}$. in the calculations.
The tap-position 0 in the model means the reactor is switched off, when the tap-position remains 1 (and the switch-breaker is open) when the physical reactor is switched off.

The simulation model is in good agreement with the test operation results, except of omitted sequences by item 6,15 16 and 19. 


\section{Coordinated Control Scheme}

Though maintained within the required static range of $+/-40$ MVAR, dynamically varying reactive power exchange via the KFE platform will introduce dynamically varying reactive-power flow in the $220 \mathrm{kV}$ AC system. Inherent voltage variation in the $400 \mathrm{kV}$ transmission grid combined with the aforementioned dynamic reactive-power flow will affect the AVR/RPC and, further, the tap-position controllers of the $220 / 33 \mathrm{kV}$ offshore wind power plant transformers. The proposed coordinated control of the AVR/RPC and the KFA and KFB WPPC shall prevent such unwished interaction between the AVR/RPC and the dynamic voltage and reactive-power conditions imposed from extern sources.

Fig. 6 shows the proposed control coordination scheme.

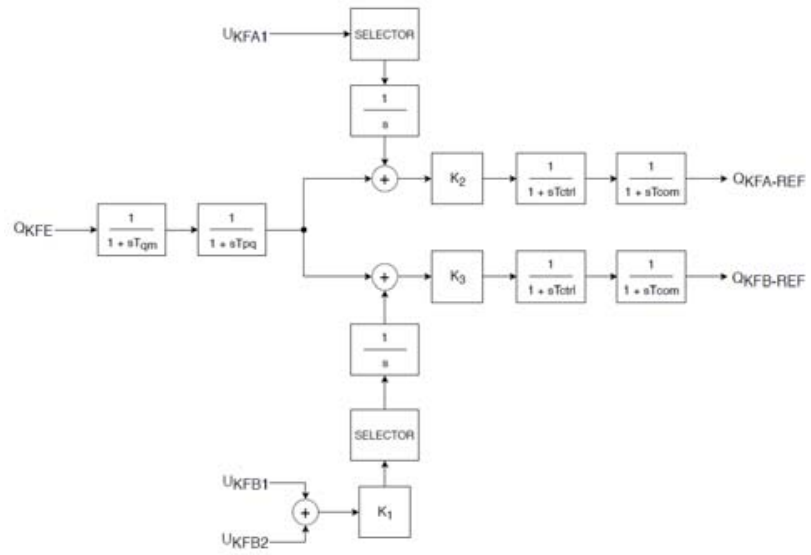

Fig. 6 Proposed voltage and reactive power coordination control scheme for the $220 \mathrm{kV}$ area of the Kriegers Flak Combined Grid Solution.

The proposed scheme monitors the reactive power flow via the KFE, QKFE, and the voltages on the medium-voltage (MV, $33 \mathrm{kV}$ ) busbars of the KFA and KFB platforms, $\mathrm{U}_{\mathrm{KFAl}}$, $\mathrm{U}_{\mathrm{KFB} 1}$, and $\mathrm{U}_{\mathrm{KFB} 2}$. The proposed scheme calculates the reactive power set-points to the KFA and KFB WPPC, $\mathrm{Q}_{\text {KFAREF }}$ and $\mathrm{Q}_{\text {KFBREF. }}$ The reactive power set-points are calculated and communicated independently to each WPPC.

The MV voltage compensation scheme employing selectors and integrators, as in Fig. 6, is included for preventing excessive tap-position stepping of the $220 / 33 \mathrm{kV}$ offshore transformers in dynamically varying (active power and) reactive power exchange of the OWPPs, $\mathrm{Q}_{\mathrm{KFAREF}} \rightarrow \mathrm{Q}_{\mathrm{KFA}}$ and $\mathrm{Q}_{\mathrm{KFEREF}} \rightarrow \mathrm{Q}_{\mathrm{KFB}}$.

The gain $\mathrm{K}_{1}$ is 0.50 because of the two available voltage measurements, $\mathrm{U}_{\mathrm{KFB} 1}$ and $\mathrm{U}_{\mathrm{KFB} 2}$ at the two $33 \mathrm{kV}$ terminals of the $220 / 33 \mathrm{kV}$ offshore transformers. The gains $\mathrm{K}_{2}$ and $\mathrm{K}_{3}$ are 0.333 and 0.667 , respectively, representing the $200 \mathrm{MW}$ and $400 \mathrm{MW}$ power capacities of the KFA and KFB wind power plants in relation to the total $600 \mathrm{MW}$ power capacity of both WPPC control systems. The time constants are $\mathrm{T}_{\mathrm{QM}}=0.1 \mathrm{~s}$, $\mathrm{T}_{\mathrm{PQ}}=0.1 \mathrm{~s}$ and $\mathrm{T}_{\mathrm{COM}}=0.1 \mathrm{~s}$, and the control time is $\mathrm{T}_{\mathrm{CTRL}}$ $=2.5 \mathrm{~s}$.

\section{Results}

This section compares the results of two cases with and without the proposed scheme, respectively. Relevance of the proposed coordination control scheme is been demonstrated by simulations on the $220 \mathrm{kV}$ area model of the KF CGS, which includes validated models of the AVR/RPC and WPPC. The inputs of the simulation model are: (i) the 400 $\mathrm{kV}$ system voltage by historical measurements for the East Danish transmission grid, (ii) the forecasted wind power production and (iii) the forecasted active and reactive power transports via the KFE platform of Energinet. Fig. 7 presents the simulation model inputs, which are identical for both compared cases.

The outputs of the simulation model are: (i) the tap-position dynamics of the $220 / 33 \mathrm{kV}$ transformers of KFA and KFB, (ii) the tap-position dynamics of the 400/220/10 kV transformers, and (iii) the tap-positions of the reactors in the compensation substation in Bjæverskov. Fig. 8 presents the simulation model outputs for the case without the proposed scheme. Fig. 9 shows the outputs with the proposed scheme. The simulation period is 30 days.

As seen from the comparison of Fig. 8 and Fig. 9, the proposed scheme achieves the main target which is prioritised reduction of the tap-position usage: (i) first, tapposition stepping of the offshore transformers shall be minimized, (ii) second, tap-position stepping of the two onshore transformers shall be reduced, (iii) third, when possible, tap-position stepping and switching of the onshore reactors shall be reduced.

The offshore transformers get the highest priority because of significant maintenance cost of the offshore assets compared to the onshore assets. The onshore transformers get the next highest priority because these transformers are needed for the full utilization of the transfer through the grid-connection and through the interconnector. The onshore reactors get the lowest priority because the KF CGS system can still be operated with some violation of the reactive power bands, though over a restricted period.

In the presented simulations, the proposed coordination control scheme has fully stopped tap-position stepping of the offshore transformers and significantly reduced tap-position stepping of the onshore transformers, which is an excellent outcome. However, utilization of the reactors is almost unchanged. 


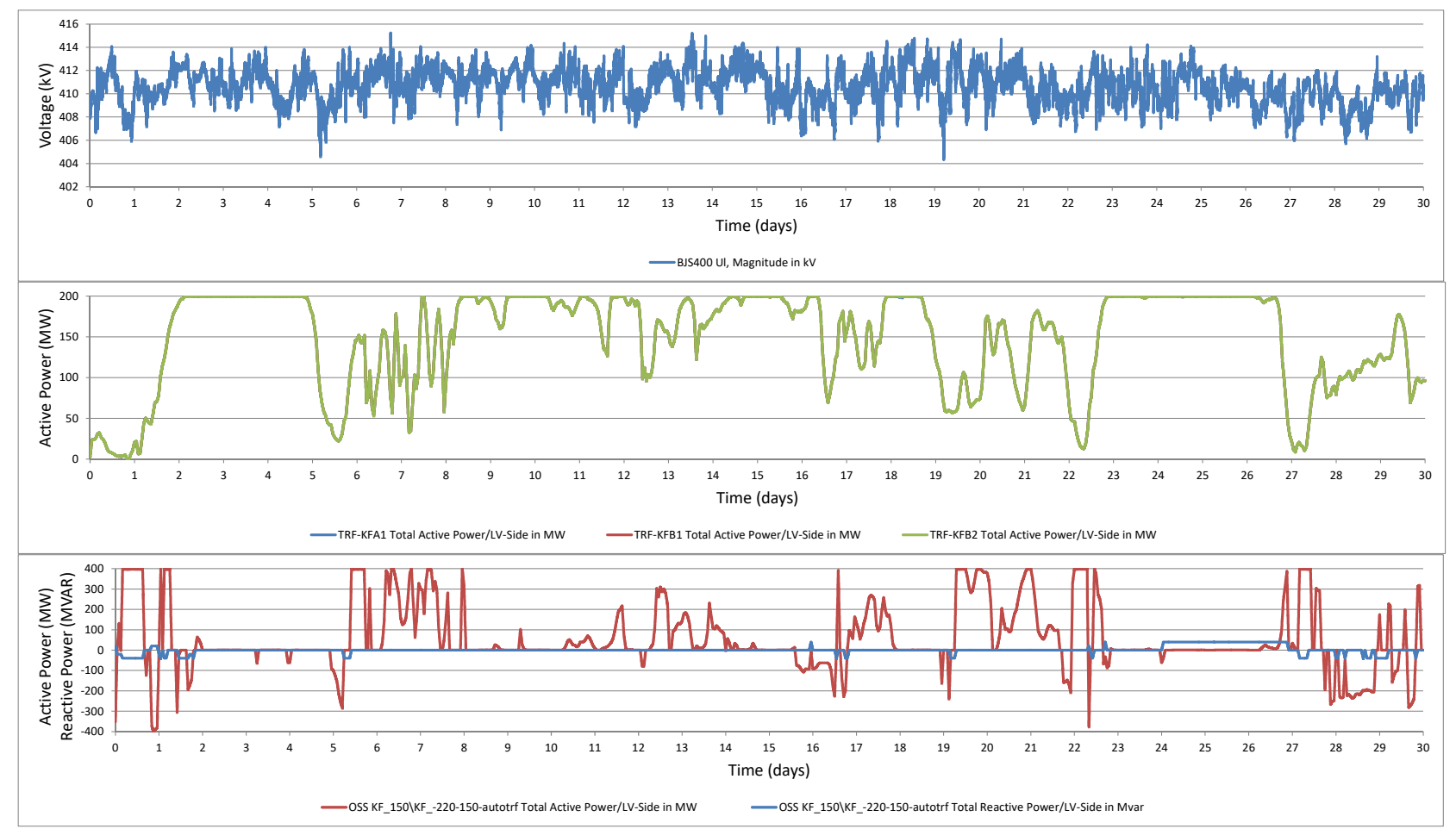

Fig. 7 Inputs: $400 \mathrm{kV}$ transmission system voltage, wind power production in each $200 \mathrm{MW}$ section (KFA is a single section and KFB are two sections), and active and reactive power via KFE platforms.

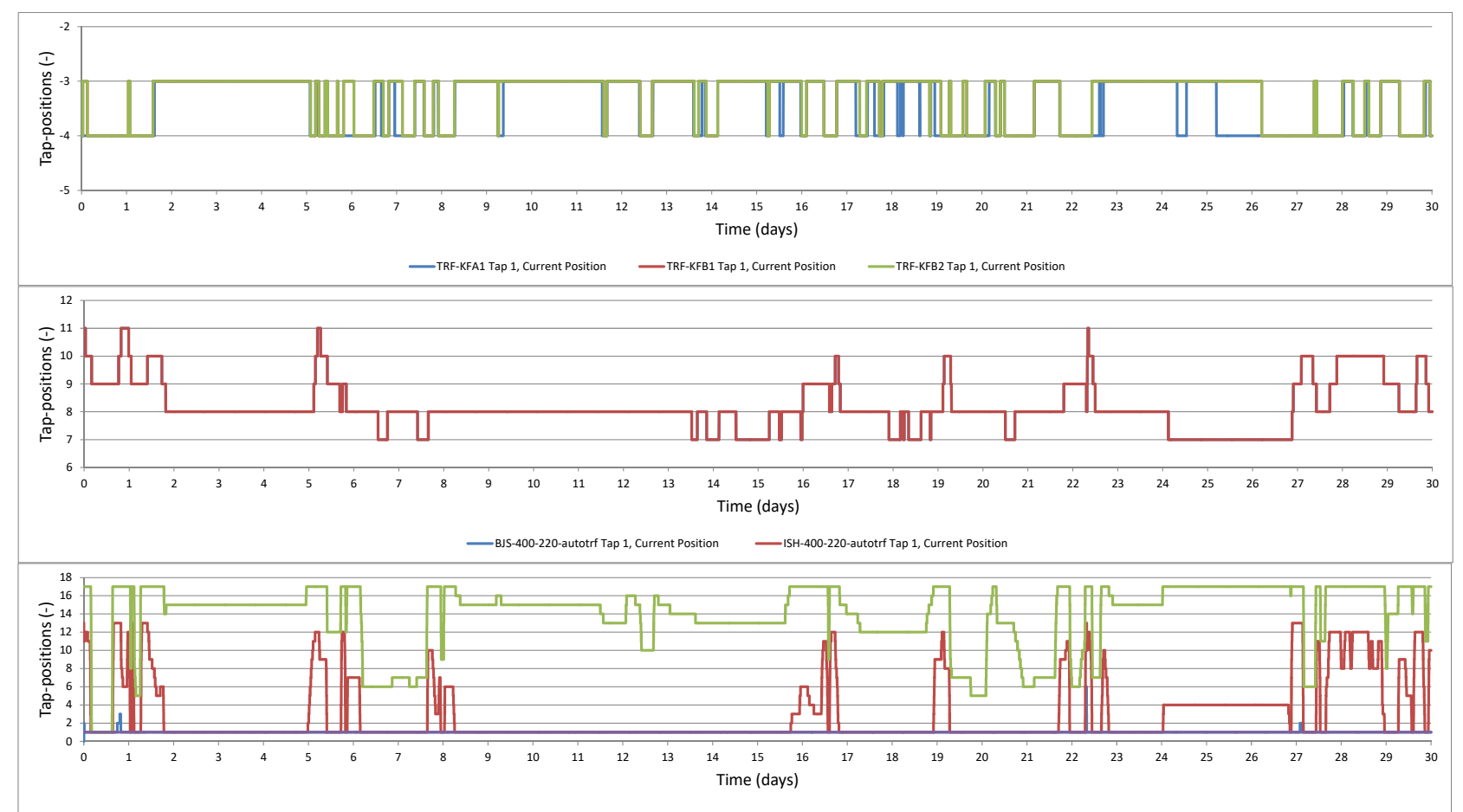

Fig. 8 Outputs without coordination control scheme: 220/33 kV offshore transformer tap-positions, 400/220/10 kV transformer tap-positions, and reactors tap-positions in substation Bjæverskov. 


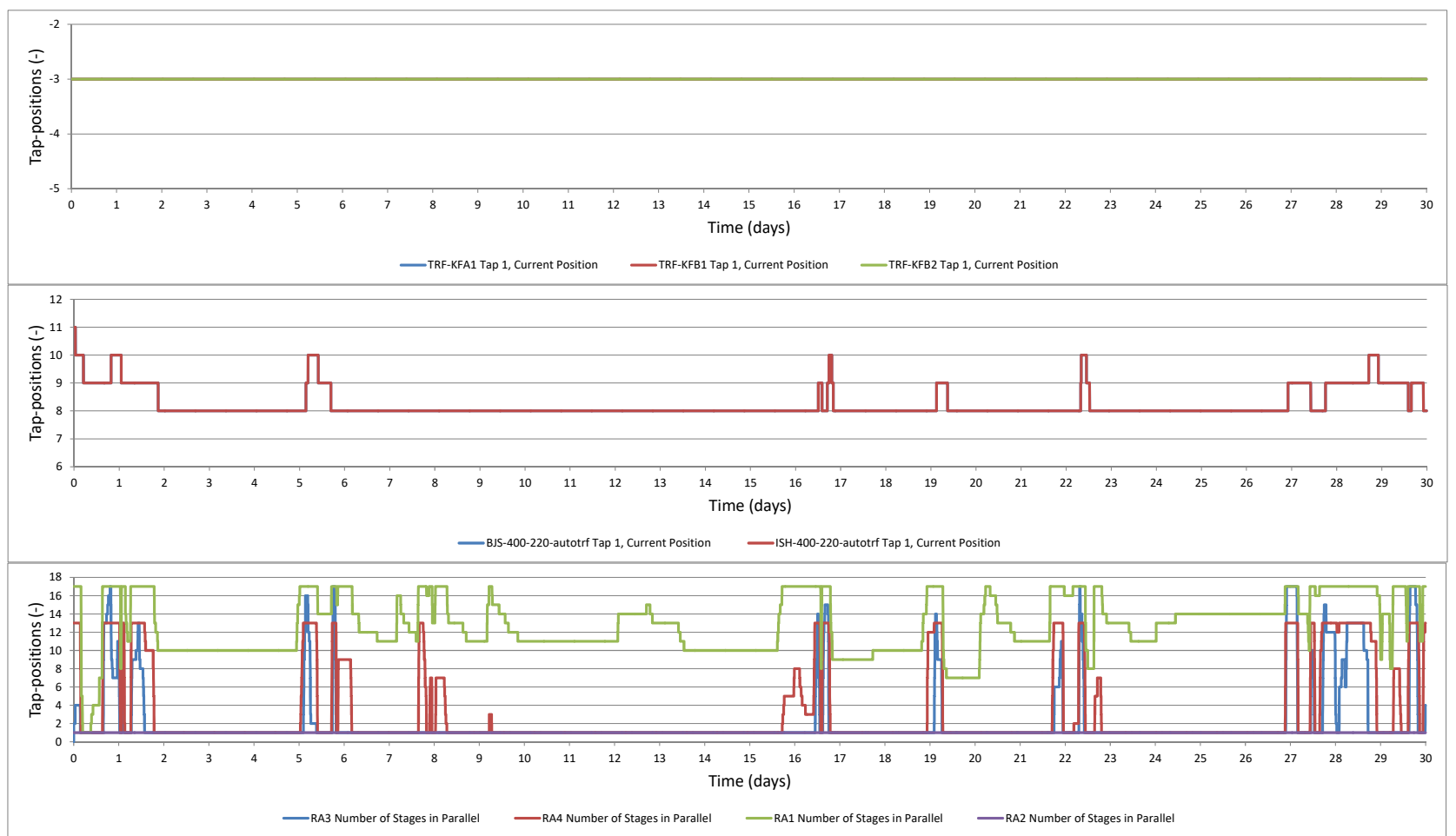

Fig. 9 Outputs with coordination control scheme: 220/33 kV offshore transformer tap-positions, 400/220/10 kV transformer tap-positions, and reactors tap-positions in substation Bjæverskov.

\section{Conclusion}

The Kriegers Flak Combined Grid Solution is the first hybrid-asset interconnector which integrates the OWPPs in the Baltic Sea and connects East Denmark and Germany through using HVAC transmission and an HVDC BtB converter. The structure of the voltage and reactive power control of this hybrid-asset interconnector has been discussed, and the main focus has been the control design, validation and coordination within the $220 \mathrm{kV} \mathrm{AC}$ transmission area with connection to the Danish transmission grid.

The automatic voltage and reactive power control (AVR/RPC) is the main control system of the $220 \mathrm{kV} \mathrm{AC}$ area. The control principles of this control system have been described and the simulation model has been successfully validated from the test operation conducted by the Danish National Control Centre of Energinet on May $2^{\text {nd }} 2019$.

The coordination control scheme utilizing the AVR/RPC together with the WPPC has been described. Efficiency of this control scheme has been confirmed by simulations using the validated models of the AVR/RPC and the models of the WPPC. Combination of historical data of varying voltages in the Danish transmission grid, wind production and transport forecasts via the interconnector, and the long periods of the simulations by 30 days, i.e., one calendar month, are among novices of the presented tests.

\section{References}

[1] European Commission, 'Offshore wind - Baltic-Kriegers Flak: Combined grid solution', [Online] Available: https://ec.europa.eu/energy/eepr/projects/files/offshore-windenergy/baltic-kriegers-flak_en.pdf, August 2018. accessed 09 May 2019

[2] Marten, A.-K., et al., 'Kriegers Flak - Combined Grid Solution: Coordinated cross-border control of a meshed HVAC/HVDC offshore wind power grid', IET Renewable Power Generation DOI: 10.1049/iet-rpg.2017.0792, Online ISSN 1752-1424 Available online: 19 February 2018.

[3] Akhmatov, V., 'Automatic voltage and reactive power control of Kriegers Flak offshore wind power plant gridconnection system', Offshore Wind Conference 2017, PO0255, London, UK, June 6-8 2017. 10 p.

[4] Olsen, R.S., 'Dynamic Loadability of Cable Based Transmission Grids', PhD Thesis, Technical University of Denmark, 2013, 284 p. 